\title{
ОСОБЛИВОСТІ ОРГАНІЗАЦІЇ ХІРУРГІЧНОЇ ДОПОМОГИ ТА ЛІКУВАЛЬНО-ЕВАКУАЦІЙНИХ ЗАХОДІВ В УМОВАХ ПАНДЕМІЇ COVID-19
}

\author{
Я.М. Било1, 0.М. Попова ${ }^{1}$, 0.0. Микита² \\ ${ }^{1}$ Військово-медичний клінічний центр Східного регіону, м. Дніпро, Україна \\ 2Українська військово-медична академія, м. Київ, Україна
}

Вступ. Надання хірургічної допомоги та ефективне здійснення лікувально-евакуаційних заходів в умовах пандемії є актуальним питанням, яке потребує розробки нової концепції інфекційного контролю $і$ формування безпечного середовища для пацієнта та персоналу.

Мета роботи - вивчити особливості організації надання хірургічної допомоги та здійснення лікувально-евакуаційних заходів в умовах пандемії COVID-19.

Матеріали та методи. За допомогою історичного, бібліографічного і порівняльного аналізу та системного підходу проведено узагальнення даних літератури стосовно санітарно-епідеміологічних та лікувально-евакуаційних заходів в умовах пандемії нової коронавірусної інфекції у Збройних Силах України.

Результати. $B$ статті розглянуто матеріали сучасних світових стандартів з цього питання $i$ узагальнено власний досвід Військово-медичного клінічного центру Східного регіону. 3 врахуванням стандартів і настанов Всесвітньої організації охорони здоров'я та Центру з контролю і профілактики захворювань, запропоновано ранжований підхід до визначення можливості, доцільності та безпеки виконання хірургічних втручань у 303 Мо України. Та запропоновано порядок організації надання хірургічної допомоги та здійснення лікувально-евакуаційних заходів в умовах пандемії COVID-19. Особлива увага приділена поділу пацієнтів на категорії, в залежності від конкретної клінічної ситуації та якомога більш ранньому розділенню потоків хворих і виключення можливості їх змішування.

Висновки. Для безпечної організації надання хірургічної допомоги та лікувально-евакуаційних заходів в умовах пандемії COVID-19, необхідно забезпечити: суворий контроль санепід режиму та заходів інфекційного контролю; “повітряну ізоляцію»; мінімізацію контактів; розділення потоків хворих на «чистих» та потенційно заражених; чітку пріоритетизацію виконання процедур; ранжоване надання допомоги. Для цього було запроваджено і має підтримуватись: суворе обмеження доступу сторонніх осіб на територію закладів охорони здоров'я (303); максимальне розвантаження госпітальної бази, розрідження хворих, ранжоване скорочення обсягу надання допомоги; посилення контролю за дотриманням санітарних вимог, заходів деконтамінації та санепіднагляду; убезпечення виконання аерозольгенеруючих процедур, в т.ч. лапароскопічних втручань; забезпечення співпрацівників засобами індивідуального захисту та контроль за їх використанням у повному обсязі; розробка чіткого алгоритму сортування і маршрутизації хворих; навчання персоналу.

Ключові слова: організація хірургічної допомоги, пандемія, COVID-19.

Вступ. Пандемія коронавірусної інфекції SARS-nCov-2019 внесла значні зміни у повсякденну роботу 303 і висунула нові вимоги до організації та забезпечення як рутинних лікувально-діагностичних процесів, так і лікувально-евакуаційних заходів у Збройних Силах України (ЗС України).

SARS-nCov-2019 не є принципово новим інфекційним агентом, а лише одним 3 представників родини коронавірусів, які, тим не менш, мають великий епідемічний потенціал. Раніше вже фіксувалися спалахи коронавірусної інфекції, зокрема описаний у 2002 році спалах SARS-CoV, що охопив понад 8 тисяч осіб, або спалах MERS-CoV на Середньому сході у 2012 році, летальність якого перевищила $30 \%[1,13,22]$.

Даний спалах коронавірусної інфекції COVID-19 характерний небаченим раніше поширенням та охопленням великого прошарку населення. Станом на 25 серпня, у світі зафіксовано понад 25 мільйонів підтверджених випадків COVID-19 та понад 840 тисяч смертей, з них близько половини - у Європейському регіоні. Летальність наразі складає $4 \%[2,13,18]$.

В Україні зафіксовано 121 тис. випадків, 3 яких понад 2,5 тис. - летальні. Кількість підтверджених випадків серед військовослужбовців $3 \mathrm{C}$ України складає близько півтори тисячі, летальних - 6 .

Мета дослідження - вивчити особливості організації надання хірургічної допомоги та здійснення лікувально-евакуаційних заходів в умовах пандемії COVID-19.

Матеріали та методи дослідження. За допомогою історичного, бібліографічного i порівняльного аналізу та системного підходу 
проведено узагальнення даних літератури стосовно санітарно-епідеміологічних та лікувально-евакуаційних заходів в умовах пандемії нової коронавірусної інфекції у Збройних Силах України.

Результати дослідження та їх обговорення. Специфіка надання хірургічноі допомоги та здійснення лікувальноевакуаційних заходів в умовах пандемії COVID19.

Серед основних чинників, що впливають на надання хірургічної допомоги та організацію лікувально-евакуаційних заходів в умовах пандемії можна виділити:

1. Перерозподіл робочої сили та персоналу [7, 8].

2. Формування процедурних пріоритетів.

3. Висока кількість аерозольгенеруючих процедур саме для групи хірургічних хворих, а отже, і вища вірогідність інфікування персоналу та пацієнтів.

4. Потенційно більша небезпека наслідків інфікування SARS-nCov-2019 в хірургічному стаціонарі через низьку мобільність та ослаблений стан хворих після оперативних втручань [15].

При плануванні заходів попередження спалаху COVID-19, нам потрібно тримати в полі зору виконання наступних стратегічних завдань: $[3,21]$.

1. Попередження і пом'якшення наслідків

2. Забезпечення загальної готовності.

3. Оперативна готовність.

4. Забезпечення

збереження, раціонального використання та відновлення ресурсів для надання допомоги $[12,22]$.

5. Створення спеціального операційного простору COVID-19, як частини більш широкого реагування для ВМКЦ та зони відповідальності.

Попередження і пом'якшення наслідків включає в себе заходи 3 інфекційного та протиепідемічного контролю, що дозволяють упередити виникнення спалаху і саме 3 них випливає загальна та оперативна готовність.

До останніх належить чітке планування заходів, організація взаємодії, навчання персоналу, розробка та відпрацювання алгоритмів ефективної роботи.

Для забезпечення продуктивності слугує аналіз та раціональний розподіл наявних ресурсів, що є запорукою якості і необхідного обсягу заходів профілактики й надання допомоги, а також дозволяє запобігти виснаженню задіяного ресурсу.
Організація надання хірургічної допомоги та здійснення лікувально-евакуаційних заходів в умовах пандемії COVID-19.

Основними стратегіями інфекційного контролю, заявленими на сьогодні В03, $€$ «повітряна ізоляція», збільшення соціальної відстані, мінімізація контактів 3 іншими людьми та розділення потоків хворих на «чистих» та потенційно заражених [19-23].

Тактично, це зводиться до вирішення наступних задач:

Максимальне зниження скупченості хворих та персоналу.

Для реалізації цього завдання необхідно обмежити обсяг допомоги, що надається, зменшивши, таким чином, навантаження на ліжковий фонд, що дозволяє по-перше, створити належні умови для ізоляції та обсервації хворих на COVID-19, у разі їх появи.

Не зважаючи на удавану простоту, реалізація цієї концепції в умовах тривалого періоду карантинних обмежень виявилася доволі проблематичною через те, що відтермінування багатьох оперативних втручань, що належать до планових, на такий тривалий термін, може призвести до критичного зростання кількості ускладнених форм хірургічної патології, зростання летальності та кількості випадків стійкої втрати боє- і працездатності.

Тому нами, відповідно до стандартів i настанов Всесвітньої організації охорони здоров'я та Центру з контролю і профілактики захворювань (Center of Diseases Prevention and Control), запропоновано ранжований підхід до визначення можливості, доцільності та безпеки виконання хірургічних втручань. Пацієнти поділяються на категорії 1-3, в залежності від конкретної клінічної ситуації:

Перша категорія поділена на 2 підгрупи:

«1а» - пацієнти, яким потрібна екстрена операція протягом 24 годин 3 метою збереження життя; та «1б» - пацієнти 3 гострими станами, які можуть мати незворотні наслідки, якщо їх не прооперувати протягом 72 годин (зокрема, кишкова непрохідність, шлунково-кишкова кровотеча 3 нестійким гемостазом та ін.).

Пацієнти пріоритету «2»- це група хворих, які мають бути оперовані протягом 4 тижнів 3 метою лікування та запобігання прогресуванню захворювання. Цих пацієнтів слід розділяти на основі клінічної невідкладності, очікуваних вторинних ускладнень. Ускладнення також можна контролювати за допомогою інтервенційних 
радіологічних або ендоскопічних процедур у випадках, коли оперативне втручання було відкладено.

Пацієнти 3 пріоритетом «3» класифікуються як ті, чиї операції можуть бути відкладені на 10-12 тижнів без негативних наслідків.

Пацієнтам третьої групи рекомендовано відтермінування оперативного втручання на період епідемії 3 періодичним динамічним контролем загального стану та основного захворювання 3 вирішенням питання про пріоретизацію втручання або подальше спостереження.

Пацієнтів «2» та «1» груп оперують у випадку, якщо кількість хворих з COVID-19 у 303 невелика, без завантаження цією групою хворих ліжок відділення реанімації.

У випадку наявності в закладах охорони здоров'я (303) хворих з COVID-19, які потребують лікування у відділенні реанімації та інтенсивної терапії, рекомендовано виконувати оперативні втручання тільки першій («1 а» та «1 б») категорії пацієнтів, за виключенням випадків, коли реанімаційне відділення заповнено повністю. Тоді надання допомоги слід скоротити до групи пацієнтів 3 пріоритетом «1 а».

Також важливим $\epsilon$ подбати про одномісне розміщення пацієнтів. Це необхідно для попередження потенційного змішування потоків хворих у разі виникнення спалаху, а також забезпечення так званої «повітряної ізоляції», що розуміє під собою зниження концентрації мікробних тіл нижче тієї, що здатна призвести до інфікування.

Необхідно виключити доступ до 303 будьяких сторонніх осіб, що не мають відношення до лікувально-діагностичного процесу (в т.ч. відвідувачів, волонтерів, журналістів).

Посилення контролю заходів гігієни, санітарно-епідемічного нагляду та деконтамінації. Скорочення обсягу аерозольгенеруючих процедур та введення спеціальних протоколів заходів безпеки при їх проведенні.

Окрім забезпечення та раціонального використання засобів індивідуального захисту для хірургічного контингенту хворих слід приділяти особливу увагу обробці побутових джерел інфікування, якими, частіше за все, $є$ дверні ручки, мобільні пристрої, а також медичний інструментарій, засоби догляду та ампули і флакони з лікарськими речовинами.

Також слід окремо наголосити на необхідності посилення заходів безпеки для персоналу при виконанні аерозольгенеруючих процедур, до яких належать:

- інтубація/екстубація;

- бронхоскопія (в т.ч. санаційна);

- гастроскопія;

- лапароскопічні втручання.

Для убезпечення персоналу, який виконує дані процедури, мають бути вжиті наступні заходи:

- максимальне скорочення чисельності задіяного персоналу та кількості процедур до мінімально необхідного;

- забезпечення персоналу додатковими засобами індивідуального захисту для виконання цих процедур;

- за можливості - використання вентиляційних систем з негативним тиском у приміщеннях, де здійснюються такі процедури;

- використання у ендоскопічних відсмоктувачах систем закритого контуру;

- використання мінімально можливого тиску карбоксиперитонеуму та димовідсмоктувачів під час лапароскопічних втручань;

- усе обладнання, яке знаходиться у приміщенні під час процедури та може використовуватись потім, складно піддається обробці (напр. апарати ЕКГ, системи моніторингу стану пацієнта тощо), перед виконанням процедури мають бути огорнуті захисною плівкою.

Якомога більш раннє розділення потоків хворих та виключення можливості їх змішування.

Наступним заходом, який має бути впроваджено, $\epsilon$ безконтактна термометрія та розгортання сортувального посту на КПП з можливістю обстеження хворого, виконання експрес-тесту на наявність антитіл до SARSnCov-2019, забору матеріалу для ПЛР, у разі необхідності - надання невідкладної допомоги. Хворі поділяються на два різні потоки відразу, що виключає вірогідність змішування потоків хворих, а отже і знижує ризик інфікування.

Для кожного потоку хворих має бути розроблений окремий маршрут. Маршрути необхідно чітко позначити та маркувати.

Також, зважаючи на велику кількість малосимптомних форм, важливим $є$ рутинне тестування на наявність антитіл до SARS-nCov2019 для усіх, без виключення хворих, навіть у випадку, коли заклад продовжує надавати планову допомогу. 
Адаптація алгоритмів надання допомоги. Необхідною є розробка чіткого алгоритму, для кожного закладу окремо, виходячи 3 його завдань, потужностей і спроможностей, порядок дій, у випадку надходження хворого, підозрілого на COVID-19. Мають бути напрацьовані конкретні схеми сортування, надання допомоги, зв'язку.

\section{Висновки}

1. Для безпечної організації надання хірургічної допомоги та лікувальноевакуаційних заходів в умовах пандемії COVID19, необхідно забезпечити: суворий контроль санепід режиму та заходів інфекційного контролю; «повітряну ізоляцію»; мінімізацію контактів; розділення потоків хворих на «чистих» та потенційно заражених; чітку пріоритетизацію виконання процедур; ранжоване надання допомоги.

2. Має підтримуватись: суворе обмеження доступу сторонніх осіб на територію 303; максимальне розвантаження госпітальної бази, розрідження хворих, ранжоване скорочення обсягу надання допомоги;

\section{Література \\ References}

1. World Health Organisation WHO Director-General's opening remarks at the media briefing on COVID-19.2020. https://www.who.int/dg/speeches/detail/who-directorgeneral-s-opening-remarks-at-the-media-briefing-oncovid-19-11-march-2020 accessed March 29, 2020.

2. Nicola, M., O'Neill, N., Sohrabi, C., Khan, M., Agha, M., Agha, R. (2020). Evidence based management guideline for the COVID-19 pandemic - review article. Int. J. Surg. Lond. Engl. https://doi.org/10.1016/i.ijsu.2020.04.001.

3. Nicola, M., Alsafi, Z., Sohrabi, C., Kerwan, A., Al-Jabir, A., Iosifidis, C., Agha, M., Agha, R. (2020). The socio-economic implications of the coronavirus and COVID-19 pandemic: a review. Int. J. Surg. https://doi.org/10.1016/i.ijsu.2020.04.018.

4. Kurihara, H., Bisagni, P., Faccincani, R., Zago, M. COVID-19 outbreak IN northern Italy: viewpoint OF the milan area surgical community. J. Trauma Acute Care Surg. 2020;1

https://doi.org/10.1097/TA.0000000000002695.

5. Brindle, M., Gawande, A. Managing, COVID-19 in surgical systems. Ann. Surg. 2020;1 https://doi.org/10.1097/SLA.0000000000003923.

6. COVIDSurg Collaborative Global guidance for surgical care during the COVID-19 pandemic: surgical care during the COVID-19 pandemic (2020). Br. J. Surg. https://doi.org/10.1002/bjs.11646.

7. Ferguson, N., Laydon, D., and other. (2020). Report 9: impact of non-pharmaceutical interventions (NPIs) to reduce COVID19 mortality and healthcare demand.

8. Stevens, S. Next steps on NHS response to COVID-19. (2020). https://www.england.nhs.uk/coronavirus/wpcontent/uploads/sites/52/2020/03/urgent-next-stepson-nhs-response-to-covid-19-letter-simon-stevens.pdf
Навчання персоналу. Кожен пункт алгоритму має бути підкріплено конкретними навичками його виконання персоналом. Поновлення знань і умінь роботи з хворими на COVID-19 має відбуватися регулярно, особливо для закладів, в яких кількість хворих $\epsilon$ невеликою.

посилення контролю за дотриманням санітарних вимог, заходів деконтамінації та санепіднагляду; убезпечення виконання аерозольгенеруючих процедур, в т.ч. лапароскопічних втручань; забезпечення співпрацівників засобами індивідуального захисту та контроль за їх використанням у повному обсязі; розробка чіткого алгоритму сортування і маршрутизації хворих; навчання персоналу.

3. Виділено три категорії пацієнтів хірургічного профілю, організація надання медичної допомоги яким в умовах пандемії COVID-19 базується на конкретній клінічній ситуації 3 встановленням пріоретизації втручання або подальшого спостереження.

9. Ziser, A., Alkobi, M., Markovits, R., Rozenberg, B. The recovery room as an intensive care unit. Crit. Care. 1998;2:P165. https://doi.org/10.1186/cc294.

10. Royal College of Surgeons of England Guidance for surgeons working during the COVID-19 pandemic. (2020). https://www.rcseng.ac.uk/coronavirus/joint-guidancefor-surgeons-v1/.

11. Schwartz, A.M., Wilson, J., Boden, S.D., Moore, T.J., Bradbury, T.L., Fletcher, N.D. (2020). Managing resident workforce and education during the COVID-19 pandemic. J. Bone Jt.Surg. https://journals.lww.com/jbjsjournal/Documents/Schwartz.pdf.

12. Dexter, F., Parra, M.C., Brown, J.R., Loftus, R.W. (2020). Perioperative COVID-19 defense: an evidencebased approach for optimization of infection control and operating room management. Anesth. Analg. https://doi.org/10.1213/ANE.0000000000004829.

13. Browne, C., Davis, N.F., Mac Craith, E.D., Lennon, G.M., Galvin, D.J., Mulvin, D.W. (2018). Prospective evaluation of a virtual urology outpatient clinic. Ir. J. Med. Sci. 187: 251254. https://doi.org/10.1007/s11845-017-1615-y.

14. Sultan, A.A., Acuña, A.J., Samuel, L.T., Rabin, J.M., Grits, D., Gurd, D.P., Kuivila, T.E., Goodwin, R.C. (2020). Utilization of telemedicine virtual visits in pediatric spinal deformity patients: a comparison of feasibility and patient satisfaction at a large academic center. J. Pediatr. Orthop. https://doi.org/10.1097/BPO.0000000000001553.

15. Connor, M.J., Winkler, M., Miah, S. (2020). COVID-19 Pandemic - is Virtual Urology Clinic the answer to keeping the cancer pathway moving? BJU Int. https://doi.org/10.1111/bju.15061.

16. Greenhalgh, T., Shaw, S., and other. (2018). Realworld implementation of video outpatient consultations at 
macro, meso, and micro levels: mixed-method study. J. Med. Internet Res. 20. https://doi.org/10.2196/imir.9897.

17. UCLPartners How-to guide: non face-to-face clinics. (2019). https://uclpartners.com/non-face-to-face-clinicsresource/.

18. General Medical Council How we will continue to regulate in light of novel coronavirus (Covid-19) (2020). https://www.gmc-uk.org/news/news-archive/how-wewill-continue-to-regulate-in-light-of-novel-coronavirus.

19. Iacobucci, G. (2020). Covid-19: all non-urgent elective surgery is suspended for at least three months in England. BMJ.: $\quad 1106$. https://doi.org/10.1136/bmj.m1106.

20. World Health Organisation Coronavirus disease 2019. https://www.who.int/emergencies/diseases/novel-coronavirus-2019.
21. European Centre for Disease Prevention and Control (ECDC) Infection prevention and control and preparedness for COVID-19 in healthcare settings. 2020. https://www.ecdc.europa.eu/en/publicationsdata/infection-prevention-and-control-andpreparedness-covid-19-healthcare-settings.

22. World Health Organisation. Aide Memoire); Geneva: 2008. Epidemic- and Pandemic-Prone Acute Respiratory Diseases Infection Prevention and Control in Health Care. https://www.who.int/csr/resources/publications/EPR AM3 E3.pdf.

23. American College of Surgeons. (2020). COVID-19: considerations for optimum surgeon protection before, during, and after operation. https://www.facs.org/covid19/clinical-guidance/surgeon-protection.

\title{
ОСОБЕННОСТИ ОРГАНИЗАЦИИ ХИРУРГИЧЕСКОЙ ПОМОЩИ И ЛЕЧЕБНО-ЭВАКУАЦИОННЫХ МЕРОПРИЯТИЙ В УСЛОВИЯХ ПАНДЕМИИ COVID-19
}

\author{
Я.М. Било, О.Н. Попова ${ }^{1}$, О.А. Микита² \\ ${ }^{1}$ Военно-медицинский клинический центр Восточного региона, г. Днепр, Украина \\ 2Украинская военно-медицинская академия, г. Киев, Украина
}

Цель работы - изучить особенности организации оказания хирургической помощи и осуществления лечебно-эвакуационных мероприятий в условиях пандемии COVID-19.

Материалы и методы. С помощью исторического, библиографического и сравнительного анализа и системного подхода проведено обобщение данных литературы по санитарно-эпидемиологических и лечебно-эвакуационных мероприятий в условиях пандемии новой коронавирусной инфекции в Вооруженных Силах Украины.

Результаты. В статье рассмотрены материалы современных мировых стандартов по этому вопросу и обобщено собственный опыт Военно-медицинского клинического центра Восточного региона. $C$ учетом стандартов и установок Всемирной организации здравоохранения и Центра по контролю и профилактике заболеваний, предложено ранжированный подход $\kappa$ определению возможности, целесообразности и безопасности выполнения хирургических вмешательств в УЗ Мо Украины. И предложен порядок организации оказания хирургической помощи и осуществления лечебно-эвакуационных мероприятий в условиях пандемии COVID-19. Особое внимание уделено разделению пациентов на категории, в зависимости от конкретной клинической ситуации, а также как можно более раннем разделению потоков больных и исключению возможности их смешивания.

Выводы. Для безопасной организации оказания хирургической помощи и лечебно-эвакуационных мероприятий в условиях пандемии COVID-19, необходимо обеспечить: строгий контроль санэпид режима и мер инфекционного контроля; “Воздушную изоляцию»; минимизацию контактов; разделение потоков больных «чистых» и потенциально зараженных; четкую приоритетизацию выполнения процедур; ранжированы оказания помощи. Для этого было введено и должно поддерживаться: строгое ограничение доступа посторонних лии на территорию УЗ; максимальная разгрузка госпитальной базы, разрежения больных, ранжированных сокращение объема оказания помощи; усиление контроля за соблюдением санитарных требований, мер деконтаминации и санэпиднадзора; страхования выполнения аерозольгенеруючих процедур, в т.ч. лапароскопических вмешательств, обеспечение сотрудников средствами индивидуальной защиты и контроль за их использованием в полном объеме; четкого алгоритма сортировки и маршрутизации больных; обучение персонала.

Ключевые слова: организация хирургической помощи, пандемия, COVID-19.

\section{FEATURES OF THE SURGICAL CARE ORGANIZATION AND MEDICAL EVACUATION MEASURES IN THE COVID-19 PANDEMIC CONDITIONS}

\author{
Ya.M. Bylo1, 0.M. Popova1, 0.0. Mykyta² \\ ${ }_{1}^{1}$ Military Medical Clinical Center of the Eastern Region, Dnipro, Ukraine \\ 2Ukrainian Military Medical Academy, Kyiv, Ukraine
}

The purpose - to study the features of the organization of the provision of surgical care and the implementation of medical and evacuation measures in the context of the COVID-19 pandemic.

Materials and methods. With the help of historical, bibliographic and comparative analysis and a systematic approach, the literature data on sanitary-epidemiological and treatment-evacuation measures in the context of a pandemic of a new coronavirus infection in the Armed Forces of Ukraine were summarized. 
Results. The article considers materials of modern world standards on this issue and summarizes the own experience of the Military Medical Clinical Center of the Eastern Region. Taking into account the standards and guidelines of the World Health Organization and the Center for Disease Control and Prevention, a ranked approach is proposed to determine the possibility, feasibility and safety of performing surgical interventions in the UZ of the Ministry of Defense of Ukraine. And the procedure for organizing the provision of surgical care and the implementation of medical and evacuation measures in the context of the COVID-19 pandemic was proposed. Particular attention is paid to the division of patients into categories, depending on the specific clinical situation, as well as the earliest possible separation of patient flows and the exclusion of the possibility of mixing them.

Conclusions. For the safe organization of the provision of surgical care and medical and evacuation measures in the context of the COVID-19 pandemic, it is necessary to ensure: strict control of the sanitary epidemiological regime and infection control measures; "Air insulation"; minimization of contacts; separation of streams of sick "clean" and potentially infected; clear prioritization of procedures; ranked assistance. For this, the following was introduced and should be supported: strict restriction of access of unauthorized persons to the territory of the UZ; maximum unloading of the hospital base, rarefaction of patients, graded reduction in the volume of care; strengthening control over compliance with sanitary requirements, decontamination measures and sanitary and epidemiological supervision; insurance for the performance of aerosol-generating procedures, incl. laparoscopic interventions, provision of health care personnel by personal protective equipment and control over their use; a clear algorithm for sorting and routing patients; training.

Key words: organization of surgical care, pandemic, COVID-19.

Конфлікт інтересів: відсутній.

Conflicts of interest: authors have no conflict of interest to daclare.

\section{Відомості про авторів:}

Било Я.М.А-В С - полковник медичної служби, начальник Військово-медичного клінічного центру Східного регіону, м. Дніпро.

Попова О.М. А-B C D - заступник начальника з клінічної роботи Військово-медичного клінічного центру Східного регіону, м. Дніпро.

Микита 0.0. CE - підполковник медичної служби, к.мед.н., доцент, доцент кафедри організації медичного забезпечення збройних сил Української військово-медичної академії, м. Київ

$A$ - концепція та дизайн дослідження; $B$ - збір даних; $C$ - аналіз та інтерпретація даних;

$D$ - написання статmі; $E$ - редагування статmі; F-остаточне затвердження статmi.

\section{Сведения об авторах:}

Било Я.М. - полковник медицинской службы, начальник Военно-медицинского клинического центра Восточного региона, г. Днепр.

Попова О.М. - заместитель начальника по клинической работе Военно-медицинского клинического центра Восточного региона, г. Днепр.

Микита 0.0. - подполковник медицинской службы, к.мед.н., доцент, доцент кафедры организации медицинского обеспечения вооруженных сил Украинской военно-медицинской академии, г. Киев.

\section{Information about authors:}

Bylo Ya.M., A-B CD - Col MS, Head of the Military Medical Clinical Center of the Eastern Region, Dnipro, Ukraine. https://orcid.org/0000-0003-4430-2951.

Popova O.M., A-BCD-Deputy Head for Clinical Work, Military Medical Clinical Center of the Eastern Region, Dnipro, Ukraine. https://orcid.org/0000-0002-3941-3609.

Mykyta 0.0., CE F - LtC MS, PhD, associate professor of the Department of Armed Forces Medical Support of the Ukrainian Military Medical Academy, Kyiv, Ukraine. https://orcid.org/0000-0002-8238-3097.

$A$ - research concept and design; $B$ - collection and/or assembly of data; $C$ - data analysis and interpretation;

$D$ - writing the article; $E$ - critical revision of the article; $F$ - final approval of the article.

Адреса для листування: вул. Московська, 45/1, буд. 33, м. Київ 01015

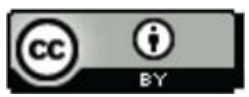

